present through a nicely concocted account of the evolution of plate-tectonic theory, and the whole delectable edifice is topped off - as might be expected of a chef from 'down under' - with a summary of the history of Warren Carey's ideas on the subject of an expanding Earth. Those familiar with Oldroyd's previous literary offerings might hope to find this new work well laced with philosophical liqueur. I can assure them that their palate will not here suffer disappointment.

Our author has carried his researches into some remote literary corners, and his 38-page bibliography must prove of inestimable value to future scholars. $\mathrm{He}$ expresses the hope that those who devour his pages will find them easier to read than he found them to write. I appreciate the problems that he faced. He had set for himself a gargantuan task. But he can rest content. His hope is fulfilled. I found the book easy and enjoyable reading, although I did crave for a splash of colour in some of the many illustrations.

Oldroyd once thought of attempting a biography of Sir Archibald Geikie, the only geologist ever to have served in the presidential chair of the Royal Society (1908-13). As I closed Oldroyd's book, it was Geikie who entered my mind. In 1896, exactly one hundred years ago, the president of Johns Hopkins University in Baltimore, Maryland, invited Geikie to inaugurate its series of George Huntington Williams memorial lectures. Geikie accepted, but one aspect of his response must surely have evoked surprise in Baltimore. Instead of devoting his discourses to some theme lifted from the core of the geological science, he proposed to lead his audiences out to graze upon pastures within the history of science. The published version of those lectures - Geikie's The Founders of Geology - proved to be highly influential. For half a century it remained the dominant work in its field.

The publication of Oldroyd's book is an important event. It is the most broadly significant English-language addition to the literature of the history of the Earth sciences since the appearance of the first edition of Geikie's work in 1897. Oldroyd's words deserve to be read - his conclusions deserve to be pondered - by all those desirous of insight into the nature of the geohistorical drama that, over the centuries, we have compiled both for human edification and for human entertainment.

Gordon L. Herries Davies, fellow emeritus of Trinity College, Dublin, is at Ballinaclough House, Ballinaclough, Nenagh, Tipperary, Ireland.

- Genesis and Geology by Charles Gillespie, first published in 1951, has just been reissued in paperback with a new foreword by Nicolaas Rupke. Harvard University Press, $\$ 17.95, £ 11.95$.
A weird world

\section{Tony Leggett}

Where Does the Weirdness Go? Why Quantum Mechanics is Strange, but Not as Strange as You Think. By David Lindley. Basic Books: 1996. Pp. 251. $\$ 24$.

THE scope and purpose of David Lindley's book is well conveyed by its title. It is quite simply an account, in entirely non-mathematical terms, of what is odd and counterintuitive about the quantum-mechanical view of the world at the level of electrons and photons, and why this same account, when extrapolated to the everyday world, does not (in the author's opinion) lead to any real difficulties or paradoxes.

These two questions take up, roughly speaking, the first three-quarters, and last quarter of the book, respectively. In the first three-quarters, Lindley for the most part does an excellent job; the writing is clear, incisive and down to earth, and succeeds remarkably well in explaining difficult concepts without using equations. There is the odd technical error, for example in the discussion of the Stern-Gerlach experiment, but these do not seriously impede the argument, and are compensated for by lucid discussions of the central points. I would put this book, along with Nick Herbert's somewhat more technical Quantum Reality, at the top of my list of accounts of atomic-level quantum mechanics for the layman.

Now to the last quarter. Lindley is a forthright (and generally lucid) adherent of the school of thought that holds that the quantum measurement paradox is completely solved by a proper consideration of the phenomenon known nowadays as 'decoherence' - roughly speaking, the inevitable 'entanglement' of macroscopic systems with their environment and the resulting scrambling of phase relations. "Decoherence, though the idea has been around for a long time [it has indeed!], has only in the last decade or so become widely accepted as an essential ingredient in understanding the apparent definiteness and irreversibility of quantum mechanics."

I think that Lindley here mistakes a sociological trend for a true intellectual development. Thirty years ago, John Bell remarked that "the typical physicist feels that [the questions related to the quantum measurement problem] have long been answered, and that he will fully understand just how if ever he can spare twenty minutes to think about it". Since 1966, 'decoherence' has merely acquired an easily memorized name and been the subject of some elegant technical developments, some of them at the hands of people who were already household names in various sub-fields of physics. Bell's "typical physicist", duly impressed by this star-studded cast, may now feel that even twenty minutes is superfluous.

If, however, we average over the community of serious students of the subject, including informed philosophers of science as well as the relevant minority of practising physicists, my impression is that discontent with the decoherence 'solution' has if anything increased over the past few years. This is certainly true in the United States, where conferences and workshops on the measurement problem are now being held with a frequency unthinkable fifteen years ago. (It is difficult to generate enthusiasm for meetings on problems generally regarded as solved.) Anyone who wants to know why should read Bell's latest paper on the problem (Physics World 3(8), 33-40; 1990), in particular his trenchant insistence that no sleight of hand can replace an "and" by an "or". Lindley refers to discontent on this point almost as an afterthought, only to confuse it with an Einstein-style hankering after determinism, a totally different issue; the central passage here utterly fails to address it, other than by simple fiat. He is, however, in distinguished company in missing what seems to me, and to a minority of other dissenters, a fundamental and crashingly obvious point.

Tony Leggett is in the Department of Physics, University of Illinois at UrbanaChampaign, Urbana, Illinois 61801, USA.

\section{Chemicals unbottled}

\author{
A. G. Cairns-Smith
}

The Natural Selection of the Chemical Elements: The Environment and Life's Chemistry. By R. J. P. Williams and J. J. R. Fraústo da Silva. Oxford University Press: 1996. Pp. 646. £75, \$145.

OverheArd: "Chemical is it? Best leave it in the bottle. Nasty things chemicals." But you can't stopper them all. The bottle is 'chemical' too. So is the shelf it is on. So is everything else that makes up our extraordinary 'ordinary world'.

Yes, but why are things around us made as they are, and of what they are? It is not always easy to say, but to provide a comprehensive guide to such answers was the heroic objective that Williams and Fraústo da Silva set themselves. The result is a tour de force, a major textbook of general chemistry, its mainly familiar topics reorganized under an obsessive theme. In this respect it is reminiscent of Pauling's The Nature of the Chemical Bond, but the theme is different and the 